\title{
Bridging tech and biotech
}

\author{
Pieter van Rooyen \\ As life science converges with big data and redefines biotech, there are more opportunities for engineers and \\ mathematicians to found life science ventures. How difficult is it to make the transition from tech to biotech?
}

\begin{abstract}
$A s$ the worlds of biomedicine, informaAtion technology and digital health intersect, numerous opportunities are opening up for new types of biotech startups. Although I trained as an electrical engineer and have built two companies focusing on wireless technology, my latest venture, Edico Genome (La Jolla, CA, USA; Box 1), lies at this intersection of biology and technology. To many in the world of high tech and information technology (IT), the world of biotech ventures and their business models might seem complex and alien. Drawing on my experience moving from wireless technology startups to the world of biotech, I provide here some tips for engineers, mathematicians and others who are thinking about making a similar leap to the world of the bioentrepreneur.
\end{abstract}

\section{My path to biotech}

During my career, I have had the fortune of working both as an academic and as a serial entrepreneur. Electrical engineering was the focus of my undergraduate and graduate studies and the subject I taught as a professor at the University of Pretoria, South Africa. This area was the basis for all of the technologies I had invented before I moved to the life sciences.

My first company was Zyray Wireless, which I founded in the summer of 2000 and which was based in Pretoria. Soon after, I made the decision to move the headquarters to San Diego, which enabled the company to capitalize on the supportive startup culture in the US and the increased credibility that building a company in the US holds, as well as gain greater access to funding and experienced engineers and people. The excellent talent pool that exists in San Diego was a great draw for me; many

Pieter van Rooyen is the co-founder and CEO of Edico Genome, La Jolla, California, USA.

e-mail:pieter@edicogenome.com experienced electrical engineers are located in San Diego because Qualcomm's headquarters are there. In San Diego, I worked with the team to build a line of advanced semiconductor and multiple antenna products for $3 \mathrm{G}$ mobile devices. In June 2004, Zyray was acquired by Broadcom (Irvine, CA, USA) for $\$ 96$ million. I became chief architect at Broadcom, working in the office of the chief technology officer for a few years before leaving and cofounding ecoATM, a San Diego-based startup that produces automated self-serve kiosks for selling back cell phones, tablets or MP3 players for cash. ecoATM was acquired by Outerwall for \$350 million in 2013.

This led me to a venture in a completely new business area, genomics (Box 1). Although my engineering background helped me visualize my new company Edico Genome, I still had to absorb an entirely new industry. This took time and patience, but through the process I picked up tips on just how it's done.

\section{Be open, humble and curious}

The key to successfully transitioning to a new field is a willingness to learn. Muhammad Ali famously said that a man who views the world the same way at 50 as he did at 20 has wasted 30 years of his life. This is especially true for bioinformatics, which encompasses many disciplines and is a rapidly evolving field. I knew I needed to learn as much as possible about life sciences, medicine and the healthcare system overall, which I did through extensive reading. But I also took full advantage of the internet, which has a plethora of good sources beyond typical search engines, such as Google, open access encyclopedia like Wikipedia, and primers on YouTube or Audible.

\section{Box 1 The genesis of Edico}

Edico Genome was a completely new direction for me, and one that arose spontaneously. I'd gone to Africa as part of a project to investigate blood screening in rural hospitals using cell phone cameras as field microscopes. The idea was to repurpose the technology for tuberculosis diagnosis, but we soon discovered that we could not do the required molecular diagnostics or sequencing in these rural locations.

It's a long-held adage that finding solutions for big problems requires diverse perspectives, and my background in electrical engineering certainly helped me see new ways around this problem. My first thought was that since the desktop sequencer was relatively small, perhaps it could be further reduced in size and become portable. But as I explored that idea, I realized that these sequencers required a huge room of expensive compute servers to analyze the data. That was when I had my 'a-ha' moment: the servers could potentially be replaced with a single dedicated processor.

That, in essence, was the birth of Edico Genome. Since then, my company has created DRAGEN, a dedicated Bio-IT processor, which contains all the algorithms needed to analyze genomes. It can replace these servers while decreasing analysis time and improving accuracy. It takes DRAGEN about 20 min to analyze a whole human genome, and we anticipate that in the future we'll be able to analyze sequencing data in real time, an initiative on which we are collaborating with Intel. There has been high demand for DRAGEN, and multiple customers have purchased the processor, including Sequenom and PerkinEImer. 


\section{Box 2 Landing an incubator}

Edico's first home was a one-room office we rented from a friend, but in short order we joined the EvoNexus incubator (San Diego). Joining an incubator is a process, but the potential benefits are worth the effort. For EvoNexus specifically, it began with submission of an application, which was then scored by a selection committee. The scoring was based upon four areas.

Market for your product. This includes size, growth presence of competitors, clarity of market focus, market need and/or acceptance.

Technology/product/service offering. How innovative/transformational the technology is, business model, sustainable competitive advantage, product development risk, ability to meet project milestones, feasibility of the technology plan, intellectual property situation.

Organization. Quality of management team, domain experience/strength, ability to attract full management team, board of directors, advisory board.

Financials. Ability to support itself while in incubator, time to revenue, ability to attract capital, including angel or institutional, sustainability outside incubator on exit.

If you are deemed by the committee to have a high enough score on the basis of these criteria, you then move on to an in-person, 10 minute presentation, followed by 10 minutes of Q\&A. Once your company makes it past that step, EvoNexus conducts additional due diligence, and if you are chosen, you are ready for incubation. The whole process took us about three months.

I read college textbooks covering chemistry, biochemistry and genomics. I dropped in at my local university and sat in on classes (after obtaining permission first, of course). Those institutions are rich sources of information as well as a good place to meet specialists in the field. But also, don't be afraid to humble yourself a bit. I bought several "For Dummies" books, which I found were well written and easy to understand. I specifically read chemistry, organic chemistry, bioinformatics and biochemistry, among others. These books gave me a healthy working knowledge of these fields.

\section{Dedication, indefatigability and persistence}

Launching a new company is not a sprint; it's a marathon. You need to be fit mentally and physically to sustain this lifestyle. Nine to five? Forget about that. Having an idea is just the first step on a long and winding road. You have to have the fortitude to put your head down and successfully navigate the process of building a company.

For example, when I started Zyray Wireless, I was the only employee that was based in the US; the rest of the team was in South Africa. We wanted to move the core team from South Africa to San Diego, but first I needed to raise money. This was not easy. What US investor would put money into a bunch of people who were not even in the US? I was rejected by almost all the initial investors I pitched to. I will never forget the words of one of these investors: "Pieter, you have nothing - go home and don't quit your teaching position at university." That was a very hard blow, but as the saying goes-if you are going through hell, keep on going. To his credit, however, that investor was the first person to congratulate me when Zyray was acquired by Broadcom.

Another great example of persistence occurred when we were pitching the idea of ecoATM. We approached 52 venture capitalists and every single one gave us a definitive no. But the 53rd venture capitalist said yes, and we never looked back.

One of the great writers of our time, Maya Angelou, said it best: "You may encounter many defeats, but you must not be defeated. In fact, it may be necessary to encounter the defeats, so you can know who you are, what you can rise from and how you can still come out of it."

\section{Ask questions and build connections}

I found it beneficial to have an ally who knew what I didn't know, and who was willing to help. This person should also have successfully transitioned into bioinformatics from a different field, and they should understand the transition process and help you navigate pitfalls.

For us, this ended up being another genomics startup, Cypher Genomics (San Diego), which was located right next to us in our incubator, EvoNexus. It was helpful to be able to discuss the genomics sector with a peer, and to go over big trends affecting the space and the problems that needed to be solved. Cypher Genomics' management team, particularly Ashley Van Zeeland, co-founder and CEO, had worked and studied the genomics industry for a long time, and they were the perfect people to help us acclimate to the space.
In a new business sector be extra proactive in building connections. As an outsider, you have to build relationships and increase your visibility in the life sciences industry. This can be achieved by attending networking events, perhaps held by the local industry trade association and reaching out to any of your existing connections. I was helped by our location in an incubator, which can be a great way to help facilitate the process of building relationships in the life sciences community (Box 2).

Two extremely important relationships we built were sparked after tours given by the incubator, specifically with Greg Lucier, the former CEO of Life Technologies, and Eric Topol, professor of genomics at The Scripps Translational Science Institute (STSI; La Jolla, CA, USA). Greg ultimately became an investor in Edico and a board member, and Eric became an advisory board member. Both are well-respected and visionary leaders who have helped guide Edico through its growth, introduced us to the right people and boosted the credibility of the company.

In addition, being located in a renowned cluster for your industry helps with connections. For us, being based in San Diego, which is home to Illumina, Thermo Fisher, Scripps Genomic Medicine at STSI and countless genomics startups, such as Portable Genomics and Cypher Genomics, was (and is) a huge advantage. Often, we are meeting people just down the street from us, and communicating in person is always more powerful than doing so by telephone or e-mail.

A final way in which we built connections (as well as credibility) with genomics-focused companies, researchers, clinicians and others using next-generation sequencing was by hiring a life sciences-focused public relations (PR) agency (Box 3). Startups often debate whether or not to bring in a PR firm for it can be very expensive. I've found that it pays for itself if your group is sharp, but to help offset the cost, try using your startup currency-equity-to pay for services that you might not be able to afford immediately. I made hiring a PR firm a priority after our first round of funding, and the results from our heightened profile were above and beyond what I anticipated.

\section{People, people, people}

I have also learned some general lessons from my startup experiences, applicable to any entrepreneur. These pertain to the people around you, and they pertain to you.

The first lesson is that every company is really about the people. I was once told, "It is better to have a C idea with an A team, than an A idea with a C team," which I absolutely believe. I can't emphasize enough that the team you assemble 


\section{Box 3 Getting the message out}

To project our new company's voice into the biotech conversation, Edico turned to PR company Canale Communications (San Diego). The firm not only worked with us to make sure our messages resonated with key audiences, but they also helped us secure media coverage of Edico across national, top life sciences industry and local media outlets.

The group also worked to secure thought leadership opportunities for me, including speaking opportunities on genomics panels at industry conferences. This increased my visibility and boosted my credibility within the life sciences industry. The public relations agency also submitted our product for key awards, including The Scientist's Top 10 Innovation list, which resulted in our selection as the number 1 innovation of the year, an honor we display on our website homepage for our customers to view.

I can say that the hiring ended up making a world of difference for us. When we meet with new customers or potential partners, there is a good chance they have already heard our name. This had a direct impact on our bottom line-selling our product.

is invaluable. Quite frankly, it boils down to a simple truth: "People don't invest in companies, they invest in people." It is easy to feel pressure to hire someone right away when you need a role filled, but it is better to wait and make sure your hire is a true fit for the company and its culture. Also, if an employee is not a good fit, cut ties sooner, rather than later. Otherwise, you will regret having someone on the team who is disruptive and doesn't fit the company culture.

If you really believe you have a great idea, make it happen. Don't accept 'no' for an answer, and persevere when those around you don't share in your belief. Remember, you will never succeed if you don't try, and every new idea seems crazy-until it works. Embrace uncertainty (and rejection). In entrepreneurship, some ideas die, some get rejected, some move forward. Statistics suggest your idea will fail. Do not dwell on this. As an entrepreneur you will constantly be faced with uncertainty, and most definitely rejection. Will you be able to raise enough money? What valuation will you get? Are you on the right track? Are you developing the right solution for the market? There are a million questions. You cannot fully know the answers, so get used to that feeling of the unknown. Don't necessarily embrace it, but don't fear it, either.

It is important to find a balance between being nimble enough to pivot when challenged, and staying firm in the face of trends and fads. The key here is to listen. It has been said that we have two ears and one tongue for a reason-so we can listen more and talk less. Think about what you are hearing and ask questions, and fine tune your vision along the way. Even if disaster strikes, remember that disaster always creates opportunity and, in turn, that opportunity creates new space for disaster. For instance, if a customer or investor doesn't like your product or proposal, that feedback is discovery, not failure. Learn from this feedback and seek insight from the reasons your idea got rejected.

\section{Join the pioneers}

As we enter a new frontier where big data converge with health, unique perspectives, expertise and approaches to problem solving are needed more than ever to overcome potential hurdles. It seems likely that in the future, life sciences companies will require a diverse talent pool working together, with geneticists working side by side with engineers and computer scientists. The intersection of these individuals will result in insights that could lead to the development of more smart, innovative products that could ultimately improve patients' lives. Do not let a background in math or engineering dissuade you from entering this burgeoning field.

\section{COMPETING FINANCIAL INTERESTS}

The authors declare no competing financial interests.

\section{First Rounders Podcast:}

\section{Colin Goddard}

Colin Goddard is former CEO of OSI Pharmaceuticals, and current chairman and CEO of Coferon. His conversation with Nature Biotechnology details the history behind OSI's blockbuster drug Tarceva (erlotinib), the benefits of having a British accent in the United States and how to survive a hostile takeover. http://www. nature.com/nbt/podcast/index.html

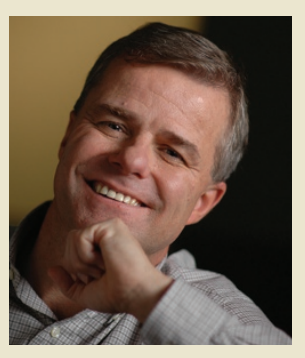

